Article

\title{
Rheological and Mechanical Properties of Silica/Nitrile Butadiene Rubber Vulcanizates with Eco-Friendly Ionic Liquid
}

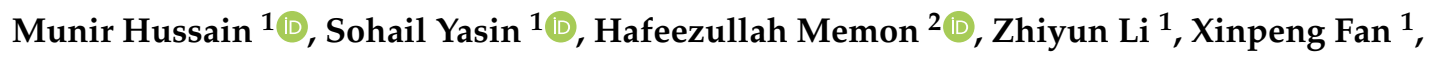 \\ Muhammad Adnan Akram ${ }^{1}$, Wanjie Wang ${ }^{3}{ }^{-}$, Yihu Song ${ }^{1, *}$ and Qiang Zheng ${ }^{1}$ \\ 1 MOE Key Laboratory of Macromolecular Synthesis and Functionalization, Department of Polymer Science \\ and Engineering, Zhejiang University, Hangzhou 310027, China; munir88@zju.edu.cn (M.H.); \\ soh.yasin@gmail.com (S.Y.); yunlemon@zju.edu.cn (Z.L.); fxpolymer@zju.edu.cn (X.F.); \\ m.adnanansari232@zju.edu.cn (M.A.A.); zhengqiang@zju.edu.cn (Q.Z.) \\ 2 College of Textile Science and Engineering (International Institute of Silk), Zhejiang Sci-Tech University, \\ Hangzhou 310018, China; hm@zstu.edu.cn \\ 3 College of Materials Science and Engineering, Henan Key Laboratory of Advanced Nylon Materials \\ and Application, Zhengzhou University, Zhengzhou 450001, China; wwj@zzu.edu.cn \\ * Correspondence: s_yh0411@zju.edu.cn
}

Received: 30 October 2020; Accepted: 18 November 2020; Published: 23 November 2020

\begin{abstract}
In this paper we designed greener rubber nanocomposites exhibiting high crosslinking density, and excellent mechanical and thermal properties, with a potential application in technical fields including high-strength and heat-resistance products. Herein 1-ethyl-3-methylimidazolium acetate ([EMIM]OAc) ionic liquid was combined with silane coupling agent to formulate the nanocomposites. The impact of [EMIM]OAc on silica dispersion in a nitrile rubber (NBR) matrix was investigated by a transmission electron microscope and scanning electron microscopy. The combined use of the ionic liquid and silane in an NBR/silica system facilitates the homogeneous dispersion of the silica volume fraction $(\varphi)$ from 0.041 to 0.177 and enhances crosslinking density of the matrix up to three-fold in comparison with neat NBR, and also it is beneficial for solving the risks of alcohol emission and ignition during the rubber manufacturing. The introduction of ionic liquid greatly improves the mechanical strength $(9.7 \mathrm{MPa})$ with respect to neat NBR vulcanizate, especially at high temperatures e.g., $100{ }^{\circ} \mathrm{C}$. Furthermore, it impacts on rheological behaviors of the nanocomposites and tends to reduce energy dissipation for the vulcanizates under large amplitude dynamic shear deformation.
\end{abstract}

Keywords: nitrile butadiene rubber; rheology; ionic liquids; tensile properties

\section{Introduction}

Nitrile butadiene rubber (NBR) with exceptional oil resistance does not possess a self-reinforcing and strain-induced crystallization effect [1]. However, nanoparticles such as carbon black or silica are extensively used to reinforce NBR vulcanizates [2]. Dispersion of nanoparticles in rubbers significantly influences the linear [3-5] and non-linear rheological behaviors [6,7] depending on nanoparticle topology, temperature, time and interfacial interactions [8-10]. The nanocomposites at low frequencies undoubtedly exhibit an apparent liquid to solid transition as filler volume fraction $(\varphi)$ increases [11,12] and, meanwhile, dynamic modulus reduces greatly with increasing strain amplitude beyond the linear viscoelastic region [13-15]. The former is termed the reinforcement effect and the latter is referred to as the Payne effect [16-18], both being long-standing topics in the fields of rheology and rubber nanocomposites. 
The properties of silica-filled rubber nanocomposites rely on the rubber-silica interfacial bonding and silica dispersion $[19,20]$. Silica nanoparticles with high surface energy and multiple silanol groups on their surface are hard to disperse homogeneously but tend to agglomerate in rubber matrices [8,21,22]. To improve the dispersity, silica is often modified via surfactant wrapping, electron beam or plasma treatments [23,24], polymer grafting and coupling agent modification [25,26]. Among many silane coupling agents bis( $\gamma$-triethoxysilylpropyl)-tetrasulfide (Si69) is one of the most commonly used one to promote the silica dispersion $[27,28]$. Silica is used to replace petrochemical fillers to reduce the environmental impacts [29]. For better dispersity of silica in rubber matrices, high amounts of silane are required [30], which, however, brings the safety risks with ethanol emission during compounding and vulcanization. Importance of sustainability in the rubber manufacturing industry is increasing, and therefore ecofriendly and sustainable agents are needed to solve these technical and safety problems associated with rubber compounding and vulcanization.

In recent years ionic liquids (ILs) have exhibited great potential in the field of science and technologies [31] for use as clean, ecofriendly chemicals and efficient alternative resources for the reduction of volatile organic solvents. They have many expectational physical, thermal, chemical and biological properties [32]. With strong chemical and thermal stability and extremely low vapor pressure, ILs can improve colloidal stability and polymer elasticity [33]. ILs are of various types, such as pyridinium-, imidazolium-, pyrrolidinium- and ammonium and phosphonium-based, etc. [34]. Imidazolium-based ILs consist of a cationic imidazolium ring and have applications in the nuclear industry, while 1-butyl-3-methyl imidazolium chloride is used as an electrolyte to recover uranium from spent nuclear fuel [35]. For ILs used in polymer nanocomposites, it is essential to understand the variations of thermodynamics and the dynamics of polymer chains. Non-volatile, low toxicity and ecofriendly ILs exhibit great potential in rubber nanocomposite formulation $[34,36,37]$ due to their ability to regulate the dispersions of fillers [38,39] and zinc oxide activators, the filler-rubber interfacial interactions [40] and the crosslinking density of the matrix, as well as the rheological, mechanical, optical, and thermal properties of the nanocomposites [41,42]. Phosphoniums demonstrate a catalyst role for the silanization reaction between silica and Si69 in styrene-butadiene rubber nanocomposites, which generally improves the silica dispersion and the silica-rubber interfacial interactions [21]. In silica filled butadiene rubber vulcanizates, the introduction of ILs (10 wt $\%$ of silica in weight) could effectively resolve the migration issue of rubber additives such as silica, sulphur and zinc oxide due to the improved interfacial interaction and crosslinking density in comparison with the traditional silane-incorporated vulcanizates [43].

Herein, ecofriendly 1-ethyl-3-methylimidazolium acetate ([EMIM]OAc) is used for the first time in silica-filled NBR vulcanizates for regulating the rheological and mechanical behaviors. It has vast applications in different fields and it may be used to mediate the NBR crosslinking reaction and silica dispersity. The results show enhancement in mechanical properties at both room temperature and high temperatures $\left(60^{\circ} \mathrm{C}\right.$ and $\left.100^{\circ} \mathrm{C}\right)$, along with improved crosslinking density and silica dispersity. The dynamic rheological analyses illuminate the effects of [EMIM]OAc on the viscoelastic nature of NBR vulcanizates.

\section{Materials and Methods}

\subsection{Materials}

A commercially available nitrile butadiene rubber (NBR, 4155C, with $41 \mathrm{wt} \%$ acrylonitrile content, $355 \mathrm{~kg} / \mathrm{mol}$ weight-averaged molecular weight and $0.97 \mathrm{~g} / \mathrm{cm}^{3}$ density) was purchased from Lanxess, Germany. Hydrophilic fumed silica (A200) with $12 \mathrm{~nm}$ diameter of primary particle and $200 \pm 25 \mathrm{~m}^{2}$ specific surface area was purchased from Evonik Degussa Co., Akron, OH, USA. $\operatorname{Bis}(\gamma$-triethoxysilylpropyl) tetrasulfide (Si69) was bought from Jessica Chem. Co., Ltd., Hangzhou, China. 1-Ethyl-3-methylimidazolium acetate ([EMIM]OAc) was supplied by Linzhou Keneng Material Co., Ltd., Linzhou, China; the structure of [EMIM]OAc is shown in Figure 1. Antioxidizing agent 
$N$-(1,3-dimethylbuty)- $N^{\prime}$-phenyl-p-phenylenediamine (6PPD) and vulcanizing agent sulphur were obtained from Anzhe Chem. Co., Ltd., Suzhou, China, and Zhejiang Yongiia Chem. Co., Ltd., Wenzhou, China, respectively. Accelerator $\mathrm{N}$-cyclohexyl-2-benzothiazolyl sulfenamide (CZ) was supplied by Tokyo Chem. Ind. Co., Ltd., Tokyo, Japan. Zinc oxide and stearic acid were purchased from Aladdin Ind. Co., Shanghai, China, and Sinopharm Chem. Reagent, Shanghai, China, respectively. All the ingredients were utilized as received without further purification except for silica that was dried for $24 \mathrm{~h}$ in an oven under vacuum condition at $110^{\circ} \mathrm{C}$.

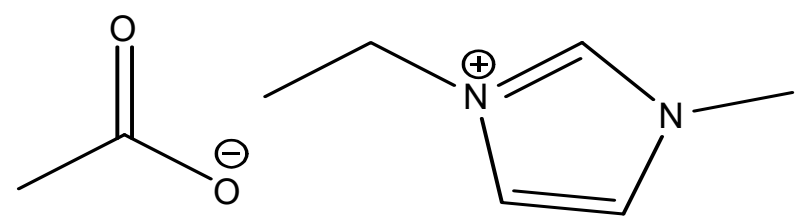

Figure 1. Structure of 1-ethyl-3-methylimidazolium acetate.

\subsection{Samples Preparation}

Ecofriendly compounds were prepared by mixing NBR with silica, silane, ionic liquid, zinc oxide, and other additives using an internal mixer (XSS-300, Kechuang Co., Ltd., Shanghai, China) at 40 revolutions per minute at $140{ }^{\circ} \mathrm{C}$ for $25 \mathrm{~min}$. At the start of mixing, the antioxidant 6PPD was added in for preventing possible thermal oxidation and degradation throughout processing and rheological investigations. Sulphur and accelerator $\mathrm{CZ}$ were mixed in the compounds for $10 \mathrm{~min}$ at $100^{\circ} \mathrm{C}$. The additives were expressed with different parts per hundred rubber (phr), as mentioned in Table 1. Si69 or Si69/[EMIM]OAc (1/1) mixture [43] was used as coupling agent for promoting silica dispersion. For further improvement of silica dispersion, the compounds were milled additionally on a two-roll mixer (XK-160, Zhanjiang Rubber and Plastic Machinery Co., Ltd., Zhanjiang, China) at room temperature. Subsequently, the compounds were compressed on a vulcanizer (XL-25, Xinli Rubber Machinery Co., Ltd., Huzhou, China) at $10 \mathrm{MPa}$ and $140 \pm 5{ }^{\circ} \mathrm{C}$ for $30 \mathrm{~min}$ into sheets of $2.0 \mathrm{~mm}$ in thickness. The sheets were cut into discs of $25.0 \mathrm{~mm}$ in diameter for rheological testing.

Table 1. Compositions of the nanocomposites.

\begin{tabular}{cc}
\hline Ingredients & Amounts (phr) $^{\text {a }}$ \\
\hline Nitrile butadiene rubber (NBR) & 100 \\
Silica & $0,10,20,30,40,50$ \\
Si69 $^{\text {b }}$ or Si69/[EMIM]OAc ${ }^{c}(1 / 1)$ & $0,0.46,0.83,1.15,1.43,1.67$ (10 wt $\%$ of silica) \\
Antioxidant 6PPD ${ }^{\mathrm{d}}$ & 1 \\
Zinc oxide $_{\text {Steric acid }}$ & 2 \\
Sulphur & 2 \\
Accelerator CZ & 2 \\
\hline
\end{tabular}

a Parts per hundred rubber (phr), ${ }^{\mathrm{b}} \operatorname{Bis}\left(\gamma\right.$-triethoxysilylpropyl) tetrasulfide (Si69), ${ }^{\mathrm{c}}$ 1-Ethyl-3-methylimidazolium acetate ([EMIM]OAc), ${ }^{\mathrm{d}} \mathrm{N}$-(1,3-dimethylbuty)-N'-phenyl-p-phenylenediamine (6PPD), ${ }^{\mathrm{e}} \mathrm{N}$-cyclohexyl-2-benzothiazolyl sulfenamide (CZ).

\subsection{Crosslinking Density}

Crosslinking density $\left(v_{c}\right)$ of NBR in the nanocomposites was calculated according to Flory-Rehner equation [44-46]

$$
v_{c}=-\frac{\ln \left(1-v_{r}\right)+v_{r}+\chi_{1} v_{r}^{2}}{V\left(v_{r}^{1 / 3}-v_{r} / 2\right)}
$$

through equilibrium swelling in toluene at room temperature for 3 days. The swollen vulcanizates were dried in vacuum oven for $24 \mathrm{~h}$ at $60^{\circ} \mathrm{C}$. In Equation (1), $\chi_{1}=0.6$ is the Flory-Huggins interaction 
parameter, $V=106.4 \mathrm{~cm}^{3} / \mathrm{mol}$ is molar volume of toluene, and $v_{r}$ is volume fraction of rubber calculated according to:

$$
v_{r}=\frac{\left(m_{2}-M_{s} m_{0}\right) / \rho_{r}}{\left(m_{2}-M_{s} m_{0}\right) / \rho_{r}+\left(m_{1}-m_{2}\right) / \rho_{s}}
$$

Here, $m_{0}$ is weight of the fresh sample, $m_{1}$ and $m_{2}$ are weights of the swollen and dried samples, $\rho_{s}=0.87 \mathrm{~g} / \mathrm{mL}$ and $\rho_{r}=0.97 \mathrm{~g} / \mathrm{mL}$ are densities of toluene and NBR, respectively, and $M_{\mathrm{s}}$ presents silica weight fraction in the prepared nanocomposites.

\subsection{Transmission Electron Microscope}

With the help of a transmission electron microscope (TEM, JEM-1230, JEOL, Tokyo, Japan), morphological observation was performed at an acceleration voltage of $80 \mathrm{kV}$ to examine the dispersity of silica and zinc oxide. The samples were prepared from vulcanizates by freezing the microtome section.

\subsection{Scanning Electron Micrographs}

Morphology of the nanocomposites was observed by scanning electron microscopy (SEM, S-4800, Hitachi, Japan). The samples were fractured in liquid nitrogen and the fracture surfaces were sputter-coated with gold-palladium through a Denton Desk-1 vacuum sputter coater (Denton Vacuum, LLC, Moorestown, NJ, USA). Furthermore, mapping of chemical elements on the sample surface was conducted on SEM-energy dispersive spectroscopy (SEM-EDS) to check the distribution and migration of some ingredients in the vulcanizates.

\subsection{Mechanical Properties}

Uniaxial tensile tests were performed on an electronic universal testing machine with a furnace facility (Zwick roell Z020, Kennesaw, GA, USA) at room temperature, $60{ }^{\circ} \mathrm{C}$, and $100{ }^{\circ} \mathrm{C}$ at a crosshead velocity $50 \mathrm{~mm} / \mathrm{min}$. The specimens were cut into a dog-bone shape of $12.5 \mathrm{~mm}$ (length) $\times 2 \mathrm{~mm}$ (width) $\times 2 \mathrm{~mm}$ (thickness) in the working section. Before conducting a high-temperature test, the samples were stored for $1 \mathrm{~h}$ in the furnace.

\subsection{Rheological Measurements}

Rheological measurements were performed on a strain-controlled rheometer (ARES-G2, TA Instruments, New Castle, DE, USA) with a geometry equipped serrated texture (diameter $25 \mathrm{~mm}$ ) to prevent samples slipping, which permitted similar measurement of rheology as the use of a smooth surface plate [47]. Time sweep of the compounds was performed with a time duration of $5000 \mathrm{~s}$ at a strain amplitude $(\gamma) 0.5 \%$ and frequency $(\omega) 10 \mathrm{rad} / \mathrm{s}$ at $140{ }^{\circ} \mathrm{C}$. The non-linear responses of the vulcanizates were measured by $\gamma$-sweeps from $\gamma=0.01 \%$ to $100 \%$ at $100{ }^{\circ} \mathrm{C}$ at $10 \mathrm{rad} / \mathrm{s}$. Before carrying out the measurements, the samples were equilibrated for $5 \mathrm{~min}$. The linear responses were measured by $\omega$-sweeps from $\omega=0.0157 \mathrm{rad} / \mathrm{s}$ to $600 \mathrm{rad} / \mathrm{s}$ at $\gamma=0.03 \%$ at $100{ }^{\circ} \mathrm{C}$. Before carrying out the measurements, the samples were equilibrated for $3 \mathrm{~min}$.

\section{Results and Discussion}

\subsection{Crosslinking Density and Vulcanization Dynamics}

Commonly $v_{\mathrm{c}}$ is an important factor influencing the mechanical properties of vulcanizate nanocomposites [48]. Figure 2A shows $v_{c}$ of NBR in the vulcanizates. For the vulcanizates with Si69, $v_{c}$ increases with increasing silica volume fraction $(\varphi)$ in a narrow range from $1.5 \times 10^{-4} \mathrm{~mol} / \mathrm{cm}^{3}$ to $2.8 \times 10^{-4} \mathrm{~mol} / \mathrm{cm}^{3}$. Once [EMIM]OAc is combined with Si69, $v_{\mathrm{c}}$ becomes higher than that using Si69 only. At $\varphi=0.177, v_{c}$ even doubles. The increment of $v_{c}$ could be ascribed to the [EMIM]OAc promoted conversion of the silanol groups into silanolates, which avoids adsorption of vulcanizing ingredients on the surface of silica and increases the curing rate [49]. The ILs may react with the nitrile group of 
NBR [50] for improving the crosslinking efficiency. Furthermore, [EMIM]OAc can greatly improve dispersions of silica and zinc oxide (as will be discussed later), promote the silanization reactivity of silica, and improve the crosslinking reaction of NBR [18,39]. For the NBR gum, the induction time of vulcanization is about $200 \mathrm{~s}$, and hereafter the complex modulus $\left(G^{*}\right)$ increases with increasing vulcanization time, as shown in Figure 2B. For the nanocomposites, this time is shortened to about $80 \mathrm{~s}$ and the introduction of [EMIM]OAc does not influence the vulcanization dynamics markedly. This means that the introduction of [EMIM]OAc improves crosslinking density mainly at the very early stage of vulcanization, which is beneficial to processing and optimization of the mechanical properties of the nanocomposite.
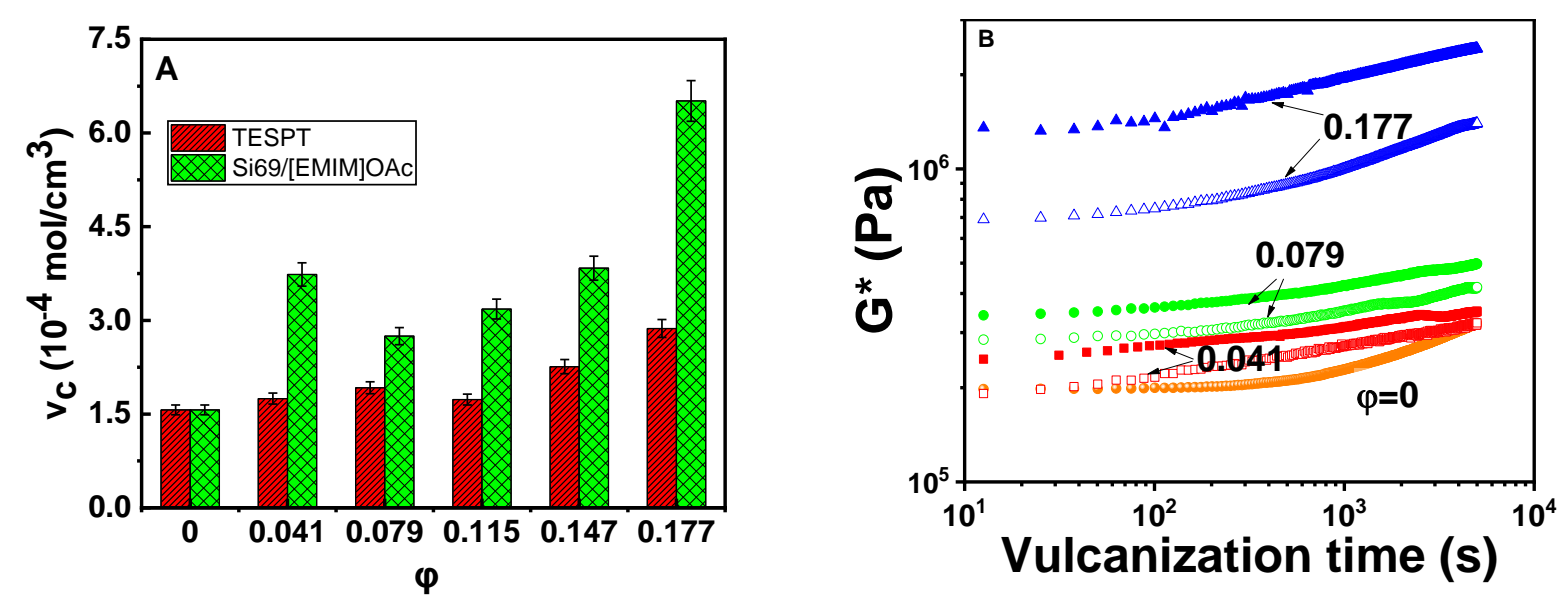

Figure 2. (A) Crosslinking density $\left(v_{\mathrm{c}}\right)$ of nitrile butadiene rubber (NBR) in the vulcanizates and (B) complex modulus $\left(G^{*}\right)$ of the nanocomposites containing bis $(\gamma$-triethoxysilylpropyl) tetrasulfide (Si69) (hollow symbols) or Si69/1-ethyl-3-methylimidazolium acetate ([EMIM]OAc) coupling agent (solid symbols) against vulcanization time.

\subsection{Dispersion of Silica and Other Additives}

Many additives are included in nanocomposite formulation and their reaction products generated during rubber vulcanization would migrate in the service of the products. In particular, the migrations of silica and curatives play a vital role in the vulcanizates, which would deteriorate the mechanical, thermal and rheological properties during service. To attain good property stability, the filler-rubber interfacial interactions should be mediated crucially $[49,51]$ while the general methodologies for the industry are not successful until the usage of ILs [43]. Figure 3 shows photographs of the compounds and vulcanizates after being stored at room temperature for one year. Differing form the silica/butadiene rubber nanocomposites [43], there is no surface staining or migration of silica and additives during the long-term storage of both the compounds and vulcanizates of NBR that contain the polar acrylonitrile unit. However, in comparison with the nanocomposites containing Si69 only, the introduction of [EMIM]OAc changes the color obviously.

Vulcanization further causes color changes especially in the case containing [EMIM]OAc. SEM-EDS elements mapping is performed to confirm the effectiveness of ILs on rubber vulcanization and silica dispersion. Figure 4 shows elements mapping at $\varphi=0.177$ (see Supplementary Materials Figure S1 for $\varphi=0.04$ ). The mapping shows clear staining, and migration of silica and the other additives onto the surface of the Si69-containing vulcanizates. The abundance of several elements on the surface of the Si69/[EMIM]OAc-containing vulcanizates is lower than those on the surface of the Si69-containing ones, revealing the improved dispersity of silica and the other additives during vulcanization of the nanocomposites containing [EMIM]OAc. 

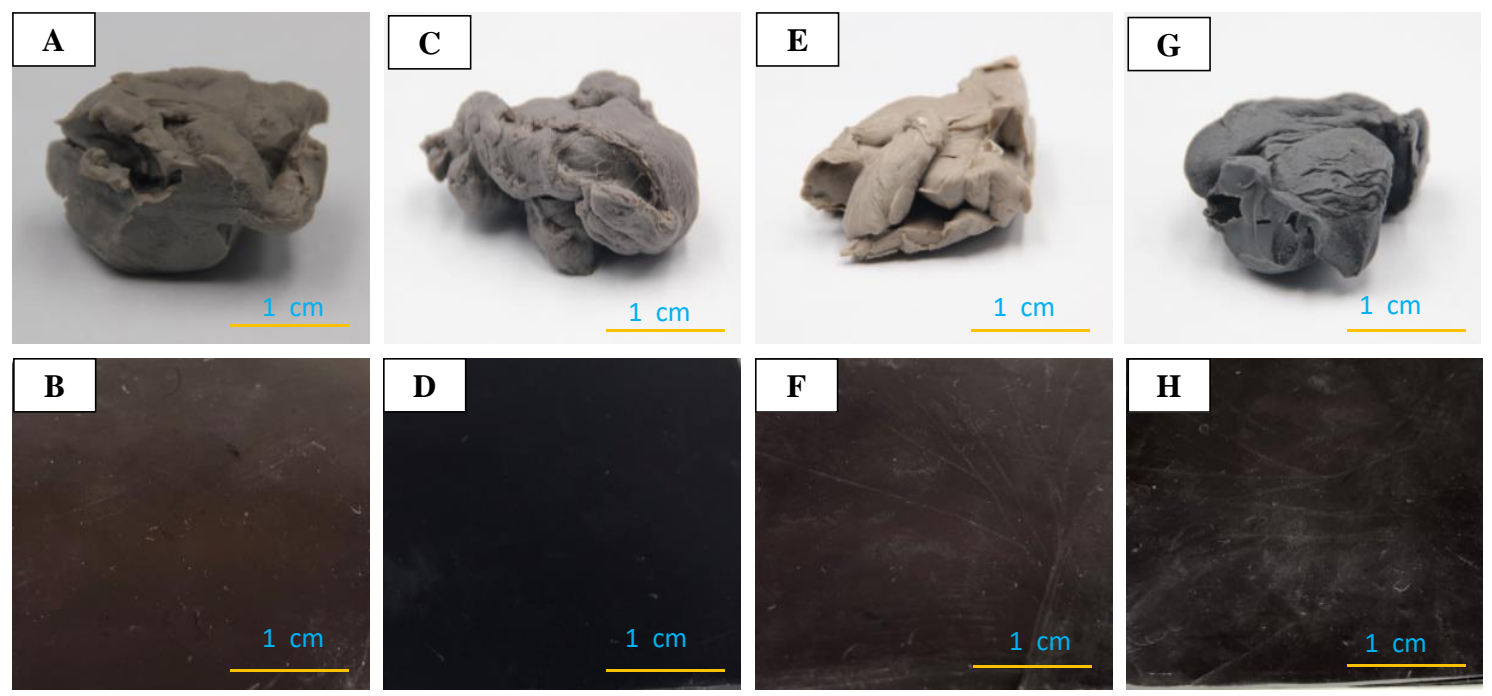

Figure 3. Photographs of one-year-stored compounds (A,C,E and $\mathbf{G})$ and vulcanizates $(\mathbf{B}, \mathbf{D}, \mathbf{F}$ and $\mathbf{H})$ comprising Si69 (A,B,E and F) or Si69/[EMIM]OAc (C,D,G and H) at $\varphi=0.04$ (A-D) and $\varphi=0.177$ (E-H). Color differences are observed for the compounds and vulcanizates and the marks on the surface of the vulcanizates are generated after separation of the mold for the compression molding.
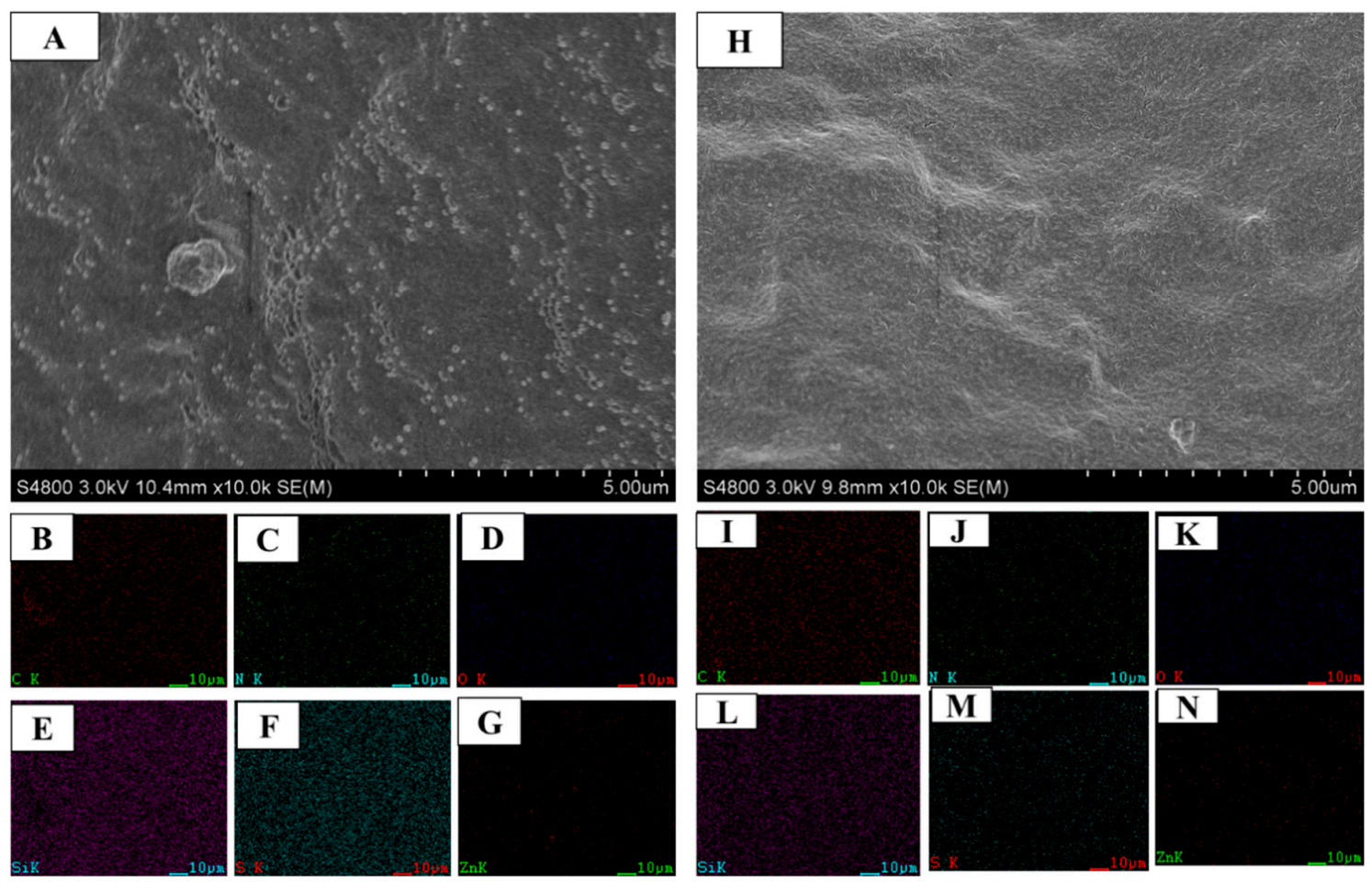

Figure 4. Scanning electron microscope (SEM) images of the vulcanizates $(\varphi=0.177)$ containing Si69 (A) or Si69/[EMIM]OAc (H) and SEM-energy dispersive spectroscopy (SEM-EDS) maps of carbon (B and $\mathbf{I})$, nitrogen (C and $\mathbf{J}$ ), oxygen ( $\mathbf{D}$ and $\mathbf{K})$, silicon (E and $\mathbf{L})$, sulphur (F and $\mathbf{M})$, and zinc elements (G and $\mathbf{N})$.

The distributions of silica, sulphur and zinc oxide and so on are further confirmed with quantitative EDS spectra (Figure 5). At $\varphi=0.04$, the spectra are similar for the Si69- or Si69/[EMIM]OAc-containing vulcanizates. At $\varphi=0.177$, the relative weight percentages of sulphur and zinc elements $(2.85 \%$ and $3.48 \%)$ on the surface of Si69-containing vulcanizates are higher than those $(2.41 \%$ and $0.09 \%)$ of the Si69/[EMIM]OAc-containing vulcanizates, revealing the significantly improved dispersion of sulphur and zinc oxide with the aid of [EMIM]OAc [52,53]. 


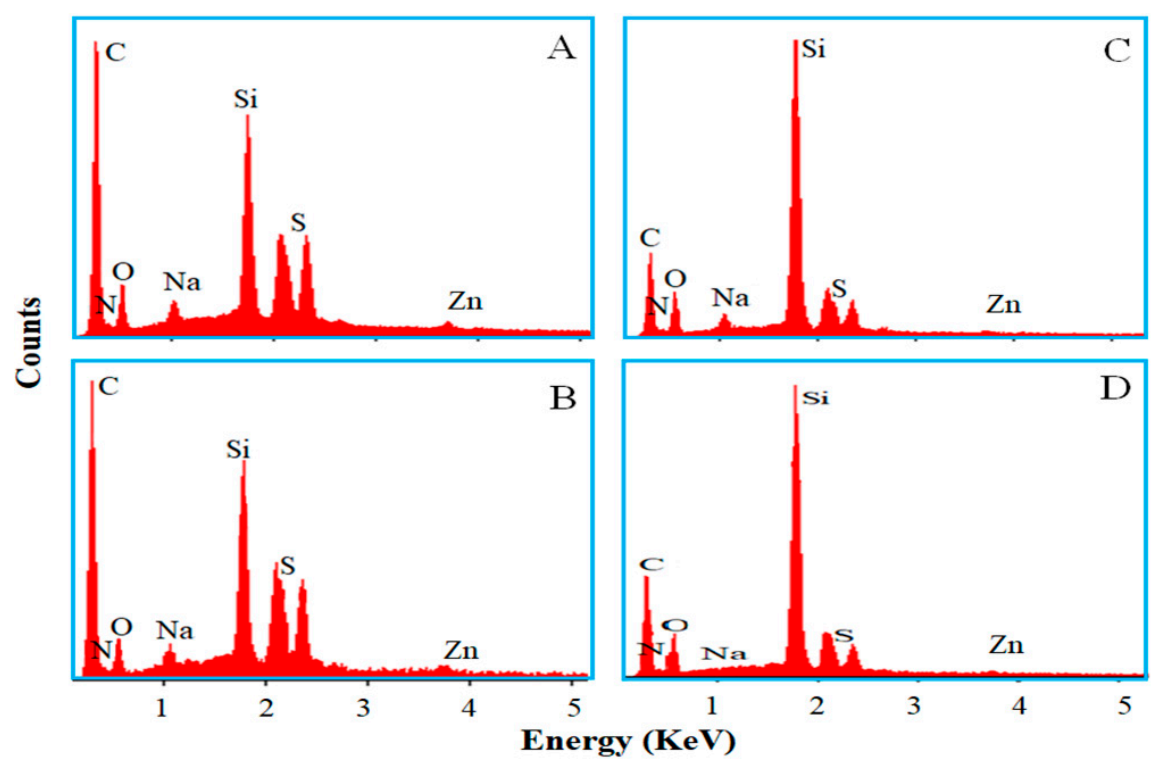

Figure 5. Energy-dispersive spectroscopy (EDS) spectra of the Si69- (A and C) and Si69/[EMIM]OAccontaining vulcanizates $(\mathbf{B}$ and $\mathbf{D})$ at $\varphi=0.04(\mathbf{A}$ and $\mathbf{B})$ and $\varphi=0.177$ (C and $\mathbf{D})$.

The improved dispersions of sulphur and zinc oxide enhance the vulcanization activity and are responsible for the higher $v_{c}$ of the Si69/[EMIM]OAc-containing vulcanizates in comparison with that of the Si69-containing ones (Figure 2A). TEM is used to evaluate the dispersions of silica and zinc oxide in the vulcanizates, as shown in Figure 6. The Si69-containing vulcanizates have few large silica agglomerates and big zinc oxide particles owing to the hydrophilic surface and low efficiency of silanization [54]. In comparison, the incorporation of Si69 and [EMIM]OAc could improve silica dispersion notably and reduce the size of zinc oxide particles efficiently. The alkaline [EMIM]OAc is expected to improve the catalytic efficiency for silanization of silica to improve the wettability of silica to NBR chains [55]. On the other hand, the zinc oxide particles with greatly reduced size exhibit improved activation to the rubber vulcanization. The modified silica dispersity and rubber vulcanization yield in mediation of mechanical properties of the vulcanizates, as will be discussed in the next section.
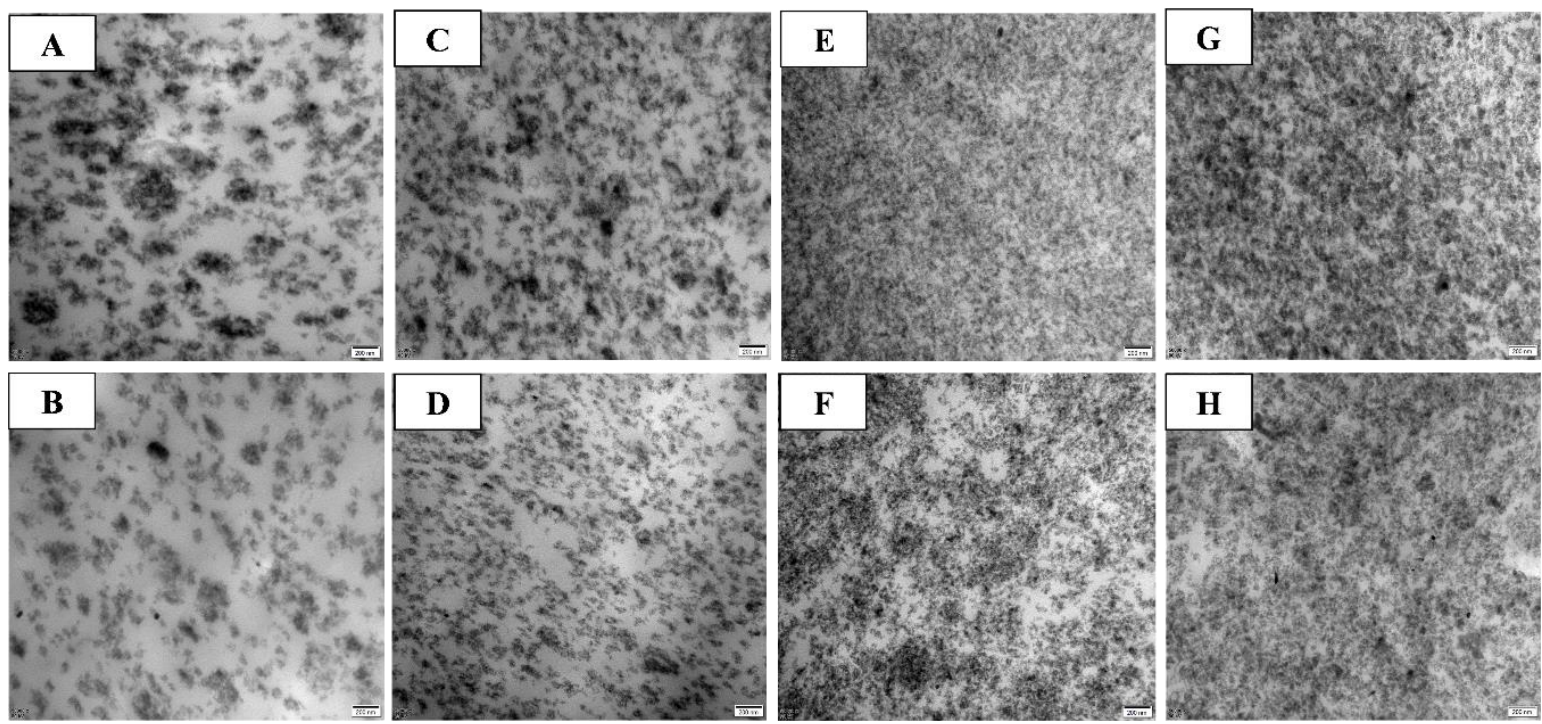

Figure 6. Transmission electron microscopy (TEM) images of the Si69- (A,C,E and G) or Si69/[EMIM]OAc-containing vulcanizates (B,D,F and H) at $\varphi=0.041$ (A and B), 0.079 (C and D), 0.147 (E and F), and 0.177 (G and $\mathbf{H})$. 


\subsection{Thermal Properties}

Glass transition temperature $\left(T_{g}\right)$ of NBR in the vulcanizates at $\varphi=0.177$ was estimated at the middle point of heat capacity jump measured by modulated differential scanning calorimetry at a heating rate of $1^{\circ} \mathrm{C} / \mathrm{min}$ [56-58] (Figure S2). In the absence of the coupling agent, $T_{g}$ of the filled vulcanizate is the same as that of the gum vulcanizate (Table S1). By addition of Si69 or Si69/[EMIM]OAc, $T_{g}$ elevates by $0.8{ }^{\circ} \mathrm{C}$ and $1.5^{\circ} \mathrm{C}$, respectively, attributed to the improved silica-rubber interfacial interaction $[59,60]$. The results suggest that [EMIM]OAc is more effective than Si69 for the creation of a strongly interacting silica-rubber interface. Thermal stability is vital in application of vulcanizates [61]. According to derivative thermogravimetry curves (Figure S3), the gum vulcanizate in nitrogen atmosphere shows decomposition peaks at $200^{\circ} \mathrm{C}$ and $383^{\circ} \mathrm{C}$, respectively. At $\varphi=0.177$, the rate of the low-temperature decomposition is reduced considerably and the high-temperature decomposition peak is shifted to $409^{\circ} \mathrm{C}$ and $412{ }^{\circ} \mathrm{C}$, respectively, when Si69 or Si69/[EMIM]OAc is used as a coupling agent. The improved thermal stability in the presence of [EMIM]OAc is associated with interfacial interaction that stabilizes NBR chains by blocking the chain ends with silica $[57,62]$.

\subsection{Tensile Properties}

The mechanical properties of rubber nanocomposites usually vary with temperature and may deteriorate greatly at relatively high temperatures. To examine the influence of temperature, tensile stress-strain behaviors at room temperature, $60{ }^{\circ} \mathrm{C}$, and $100^{\circ} \mathrm{C}$ were measured (Figure S4) $[63,64]$ and tensile strength, strain at break and stresses at $100 \%$ and $300 \%$ strains are determined. The results are listed in Table 2. Firstly, tensile strength, strain at break, and stresses at $100 \%$ and $300 \%$ strains decrease with temperature due to the weakened intermolecular interactions. Secondly, tensile strength and stresses at $100 \%$ and $300 \%$ strains increase with increasing $\varphi$, which is ascribed to the reinforcement effect and improved crosslinking density induced by the filler (Figure 2A). Thirdly, tensile strength and stresses at 100\% and 300\% strains of the Si69/[EMIM]OAc-containing vulcanizates are higher than those of the Si69-containing ones, which is ascribed to the modifications of filler dispersion and vulcanization efficiency with the aid of ILs [65-67]. The Si69/[EMIM]OAc-containing vulcanizate at $\varphi=0.177$ exhibits tensile strength of $31 \mathrm{MPa}$ at room temperature and $11 \mathrm{MPa}$ at $100{ }^{\circ} \mathrm{C}$, signifying a potential application in high-strength and heat-resistance products. The surprisingly high strength at $100{ }^{\circ} \mathrm{C}$ endowed by ILs might be ascribed to the improved crosslinking efficiency (Figure 2A) and thermal stability (Figure S3).

Table 2. Mechanical properties of NBR vulcanizate and its Si69-or Si69/[EMIM]OAc-containing nanocomposites.

\begin{tabular}{|c|c|c|c|c|c|c|c|c|}
\hline \multirow{2}{*}{$\begin{array}{c}\text { Coupling Agent } \\
\varphi\end{array}$} & & \multirow{2}{*}{$\begin{array}{l}1 \\
0\end{array}$} & \multicolumn{3}{|c|}{ Si69 } & \multicolumn{3}{|c|}{ Si69/[EMIM]OAc } \\
\hline & & & 0.041 & 0.079 & 0.177 & 0.041 & 0.079 & 0.177 \\
\hline \multirow{3}{*}{$\begin{array}{c}\text { Strain at break } \\
(\%)\end{array}$} & $100^{\circ} \mathrm{C}$ & $409 \pm 143$ & $409 \pm 143$ & $409 \pm 143$ & $409 \pm 143$ & $409 \pm 143$ & $409 \pm 143$ & $409 \pm 143$ \\
\hline & $60^{\circ} \mathrm{C}$ & $572 \pm 19$ & $357 \pm 19$ & $369 \pm 5$ & $600 \pm 43$ & $252 \pm 19$ & $360 \pm 32$ & $563 \pm 12$ \\
\hline & RT & $659 \pm 48$ & $540 \pm 31$ & $614 \pm 18$ & $566 \pm 82$ & $472 \pm 19$ & $512 \pm 32$ & $559 \pm 47$ \\
\hline \multirow{3}{*}{$\begin{array}{l}\text { Tensile strength } \\
\text { (MPa) }\end{array}$} & $100^{\circ} \mathrm{C}$ & $1.5 \pm 0.2$ & $2.4 \pm 0.3$ & $4.1 \pm 0.2$ & $8.5 \pm 0.7$ & $2.7 \pm 0.1$ & $5.0 \pm 0.3$ & $11.2 \pm 1.0$ \\
\hline & $60^{\circ} \mathrm{C}$ & $2.5 \pm 0.3$ & $4.0 \pm 0.3$ & $5.1 \pm 0.2$ & $14.4 \pm 1.3$ & $4.3 \pm 0.4$ & $9.8 \pm 1.6$ & $19.6 \pm 1.5$ \\
\hline & RT & $6.4 \pm 0.8$ & $14.1 \pm 2.1$ & $20.9 \pm 0.9$ & $25.5 \pm 1.5$ & $17.4 \pm 1.9$ & $25.1 \pm 1.8$ & $31.0 \pm 1.3$ \\
\hline \multirow{3}{*}{$\begin{array}{l}\text { Stress at } 100 \% \text { strain } \\
(\mathrm{MPa})\end{array}$} & $100^{\circ} \mathrm{C}$ & $0.89 \pm 0.1$ & $1.5 \pm 0.1$ & $1.6 \pm 0.1$ & $2.0 \pm 0.1$ & $2.36 \pm 0.2$ & $2.3 \pm 0.2$ & $3.2 \pm 0.5$ \\
\hline & $60^{\circ} \mathrm{C}$ & $0.59 \pm 0.09$ & $1.24 \pm 0.09$ & $1.42 \pm 0.1$ & $2.42 \pm 0.23$ & $1.73 \pm 0.24$ & $2.15 \pm 0.30$ & $2.56 \pm 0.20$ \\
\hline & RT & $0.85 \pm 0.10$ & $1.48 \pm 0.14$ & $1.97 \pm 0.2$ & $2.84 \pm 0.16$ & $2.22 \pm 0.7$ & $2.97 \pm 0.6$ & $4.22 \pm 0.8$ \\
\hline \multirow{3}{*}{$\begin{array}{l}\text { Stress at } 300 \% \text { strain } \\
\qquad(\mathrm{MPa})\end{array}$} & $100^{\circ} \mathrm{C}$ & $1.61 \pm 0.16$ & $2.64 \pm 0.43$ & $4.31 \pm 0.14$ & $6.23 \pm 0.34$ & $2.85 \pm 0.42$ & $5.37 \pm 0.34$ & $9.90 \pm 0.70$ \\
\hline & $60^{\circ} \mathrm{C}$ & $1.43 \pm 0.20$ & $3.22 \pm 0.30$ & $4.14 \pm 0.17$ & $7.08 \pm 0.46$ & $4.67 \pm 0.60$ & $8.05 \pm 0.80$ & $8.64 \pm 0.50$ \\
\hline & RT & $1.92 \pm 0.30$ & $4.58 \pm 0.40$ & $6.69 \pm 0.34$ & $11.2 \pm 0.8$ & $8.0 \pm 0.2$ & $11.5 \pm 1.1$ & $14.8 \pm 0.9$ \\
\hline
\end{tabular}

\subsection{Rheological Behaviours}

Rheological responses of the vulcanizates are dependent on the composition. Figure 7 shows the linear rheological response at $\gamma=0.03 \%$. Storage modulus $\left(G^{\prime}\right)$, loss modulus $\left(G^{\prime \prime}\right)$ and loss tangent $(\tan \delta)$ of the gum vulcanizate are weakly dependent on frequency $(\omega)$ [68], which is ascribed to the 
relaxation of a non-ideally crosslinked molecular network. Filling in general elevates both $G^{\prime}$ and $G^{\prime \prime}$ except for a reduction of $G^{\prime \prime}$ at high $\omega$ for the nanocomposites at $\varphi=0.041$. The introduction of silica at $\varphi=0.041$ greatly reduces $\tan \delta$ and the effect is more marked in the presence of Si69/[EMIM]OAc than Si69 only as the coupling agent. With increasing $\varphi, \tan \delta$ of the vulcanizates increases due to the relaxation associated with interparticle and filler-rubber interfacial frictions. The comparison of rheological data at $\omega=120 \mathrm{rad} / \mathrm{s}$ is shown in Figure 8. It is seen that the presence of Si69/[EMIM]OAc lowers $G^{\prime}, G^{\prime \prime}$ and $\tan \delta$ in comparison with the case of Si69 as a coupling agent, except for $G^{\prime}$ at $\varphi=0.177$. The $\tan \delta$ reduction is consistent with the improved filler dispersion and crosslinking efficiency, and is beneficial for alleviating the dissipation of mechanical energy during dynamic deformations.
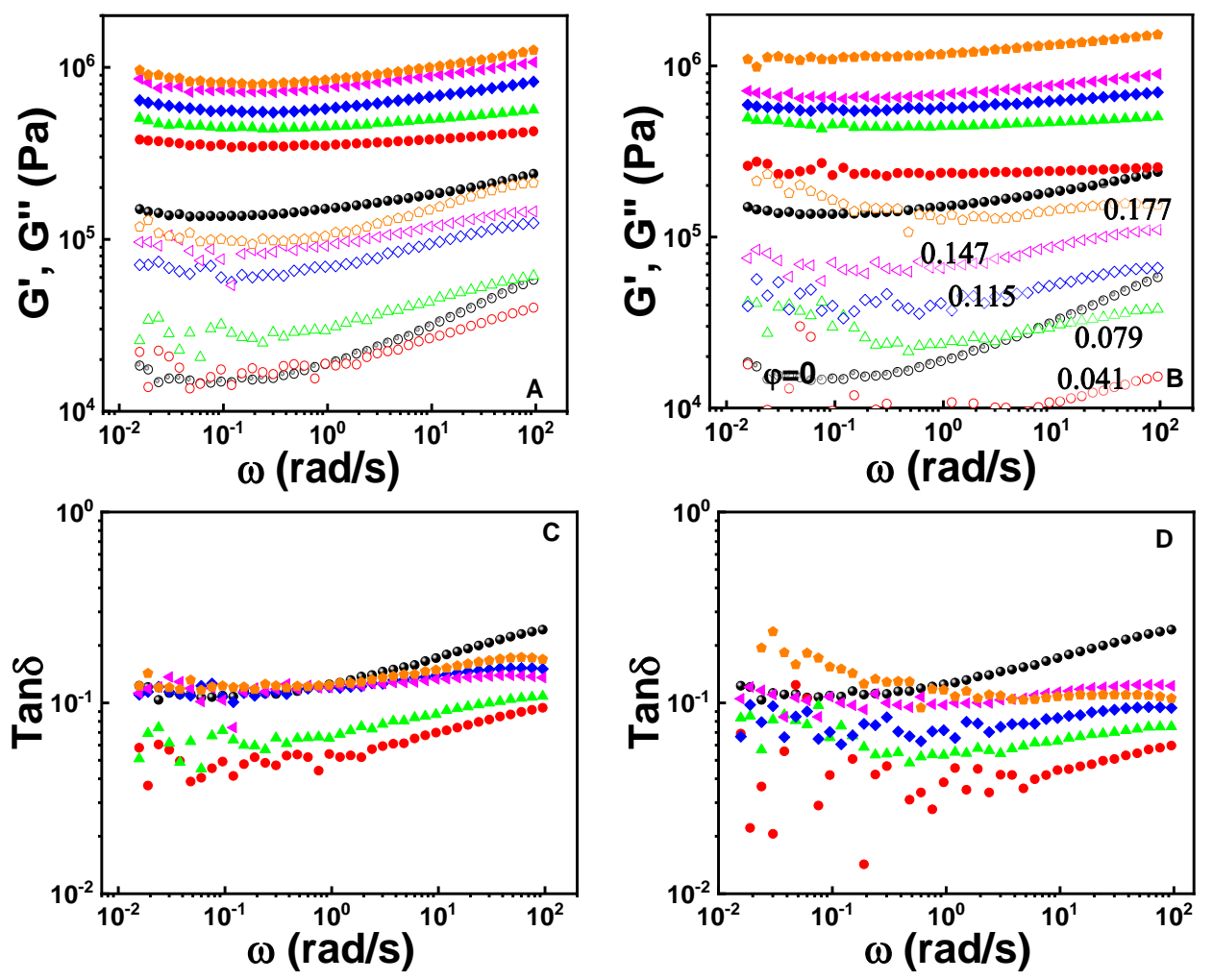

Figure 7. Storage modulus ( $G^{\prime}$, solid symbols), loss modulus ( $G^{\prime \prime}$, hollow symbols) and loss tangent $(\tan \delta)$ as a function of frequency $(\omega)$ for the gum and filled vulcanizates containing Si69 (A and C) or Si69/[EMIM]OAc (B and D) at strain amplitude $(\gamma) 0.03 \%$.
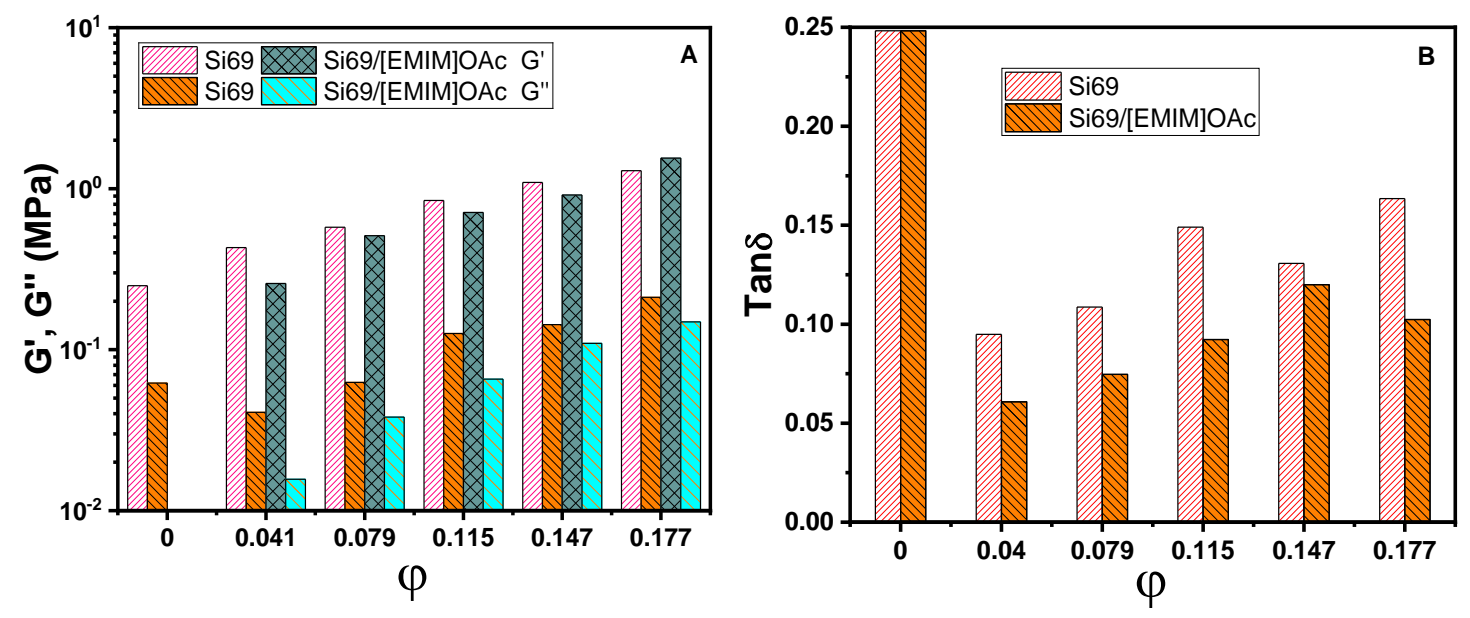

Figure 8. $G^{\prime}, G^{\prime \prime}(\mathbf{A})$ and $\tan \delta(\mathbf{B})$ as a function of $\varphi$ at $\omega=120 \mathrm{rad} / \mathrm{s}$ and $\gamma=0.03 \%$ for the gum vulcanizate and its Si69-or Si69/[EMIM]OAc-containing nanocomposites. 
Non-linear rheological responses are shown in Figure 9 for the gum and filled vulcanizates at $100{ }^{\circ} \mathrm{C}$ at $10 \mathrm{rad} / \mathrm{s}$. At low $\gamma$ all the vulcanizates present a linear viscoelastic region where $G^{\prime}$, $G^{\prime \prime}$, and $\tan \delta$ remain near constant. The linear viscoelastic region is shortened with increasing $\varphi$, which could be ascribed to the strain amplification effect arising from the filler [68-70]. Beyond the linear viscoelastic region, $G^{\prime}$ decreases and $\tan \delta$ increases rapidly with increasing $\gamma$, which is called the Payne effect $[71,72]$. Accompanying this effect, $G$ " of the gum vulcanizate exhibits a weak strain overshoot $[57,73]$ indicating the formation of a non-ideal crosslinking network containing many defects like dangling chains [47] that strengthen the intermolecular friction during dynamic deformation.
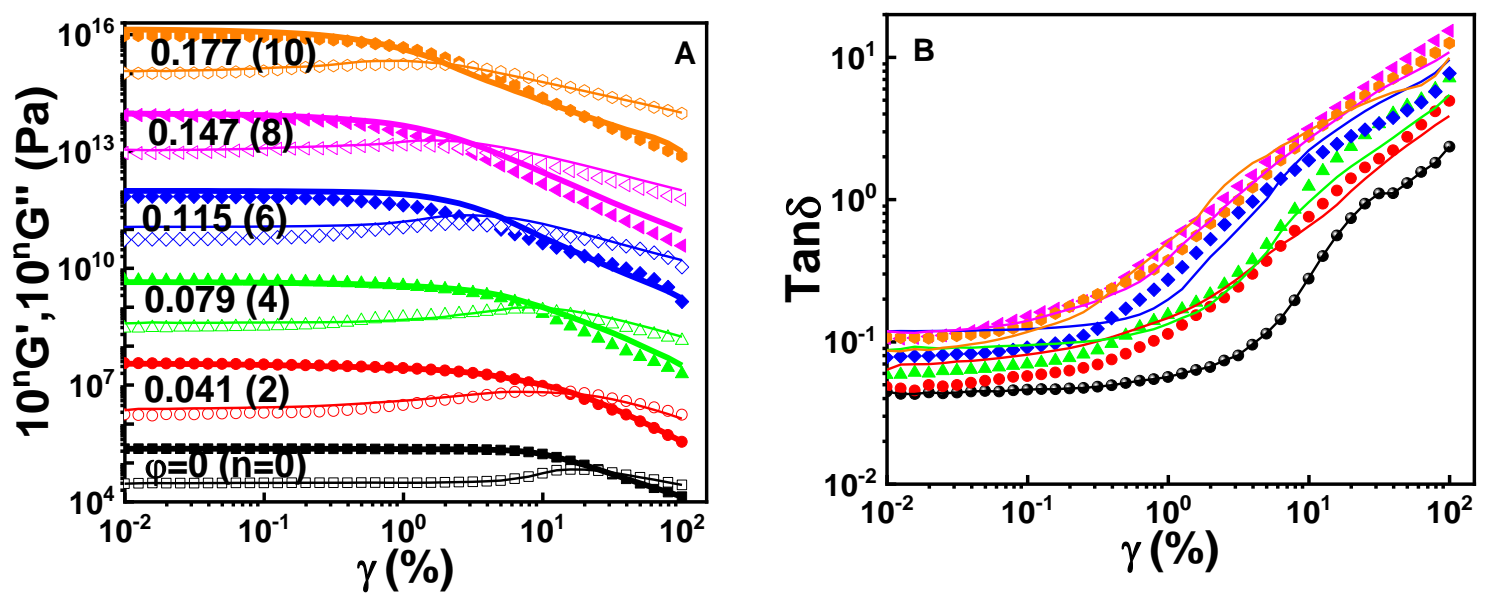

Figure 9. G' (solid symbols and thick curves, A), G" (hollow symbols and thin curves, A) and $\tan \delta$ (B) as a function of $\gamma$ for the gum and filled vulcanizates containing Si69 (curves) or Si69/[EMIM]OAc (symbols) at $100{ }^{\circ} \mathrm{C}$ and $10 \mathrm{rad} / \mathrm{s}$. The data of $G^{\prime}$ and $G^{\prime \prime}$ are vertically shifted by a factor of $10^{n}$ as indicated.

Filling causes the overshoot to become broad and gradually weakened, which could be ascribed to the adsorption of chains on the surface of silica nanoparticles. In comparison with Si69, the usage of Si69/[EMIM]OAc as coupling agent reduces $\tan \delta$ in the linear viscoelastic region but it does not influence the increment of $\tan \delta$ in the non-linear regime. This means that the Payne effect is not only dependent on the filler dispersity but also on the network of the rubber matrix.

\section{Conclusions}

In comparison with Si69, a combined usage of Si69 and [EMIM]OAc in a weight ratio of 1/1 in silica filled NBR vulcanizates can improve the crosslinking degree and filler dispersity, resulting in an improvement in tensile strength especially at high temperatures $\left(60^{\circ} \mathrm{C}\right.$ and $\left.100^{\circ} \mathrm{C}\right)$. The presence of [EMIM]OAc could decline $G^{\prime \prime}$ and $\tan \delta$ in the linear viscoelastic region, indicating a reduction of energy dissipation. Furthermore, the Payne effect does not alter markedly by introduction of [EMIM]OAc, suggesting that this effect involves both the filler dispersity and crosslinking density. The results are helpful for designing greener rubber nanocomposites with optimized crosslinking density and filler dispersity and for reducing safety risks associated with alcohol emission due to the usage of silane during rubber compounding.

Supplementary Materials: The following are available online at http://www.mdpi.com/2073-4360/12/11/2763/s1, Figure S1: SEM-EDS mapping of elements of carbon (A and $\mathrm{H})$, nitrogen (B and I), oxygen (C and J), sodium (D and K), silicon (E and L), sulphur (F and M) and zinc elements (G and N) for Si69- or Si69/[EMIM]OAc containing vulcanizates $(\varphi=0.041)$. Figure S2: Specific heat capacity of the gum vulcanizate $(\varphi=0)$ and its nanocomposites $(\varphi=0.177)$. The curves are shifted vertically for clear display. Figure S3: Derivative thermogravimetry curves of the gum vulcanizate $(\varphi=0)$ and its Si69- or Si69/[EMIM]OAc-containing nanocomposites $(\varphi=0.177)$ in nitrogen atmosphere. The curves are shifted vertically for clear display, Figure S4: Stress-strain curves for Si69- or Si69/[EMIM]OAc-containing nanocomposites at room temperature $(\mathrm{A}), 60^{\circ} \mathrm{C}(\mathrm{B})$ and $100{ }^{\circ} \mathrm{C}(\mathrm{C})$. Table S1: Glass transition temperature $\left(T_{\mathrm{g}}\right)$ of the gum vulcanizate $(\varphi=0)$ and its nanocomposites $(\varphi=0.177)$. 
Author Contributions: M.H. investigation, conceptualization, writing-original draft. S.Y. writing一review and editing. H.M. review and editing. Z.L. writing-review and editing. X.F. writing-review and editing. M.A.A. writing-review and editing. W.W. writing-review and editing. Y.S. supervision, conceptualization, writing-review and editing. Q.Z. writing-review and editing. All authors have read and agreed to the published version of the manuscript.

Funding: This work was supported by the National Natural Science Foundation of China (U1908221, 51873190, and 51790503) and the Fundamental Research Funds for the Central Universities (No. 2020XZZX002-08).

Conflicts of Interest: The authors declare no conflict of interest.

\section{References}

1. El-Nemr, K.F. Effect of different curing systems on the mechanical and physico-chemical properties of acrylonitrile butadiene rubber vulcanizates. Mater. Des. 2011, 32, 3361-3369. [CrossRef]

2. Hagita, K.; Morita, H. Effects of polymer/filler interactions on glass transition temperatures of filler-filled polymer nanocomposites. Polymer 2019, 178, 121615. [CrossRef]

3. Zheng, Z.; Song, Y.-H.; Zheng, Q. Interfacial structure and rheology of fumed silica filled polar oligomer nanocomposites. Acta Polym. Sin. 2017, 3, 429-453.

4. Song, Y.; Zheng, Q. A guide for hydrodynamic reinforcement effect in nanoparticle-filled polymers. Crit. Rev. Solid State Mater. Sci. 2016, 41, 318-346. [CrossRef]

5. García, B.F.; Saraji, S. Linear rheology of nanoparticle-enhanced viscoelastic surfactants. J. Mol. Liq. 2020, 300, 112215. [CrossRef]

6. Stockelhuber, K.; Svistkov, A.; Pelevin, A.; Heinrich, G. Impact of filler surface modification on large scale mechanics of styrene butadiene/silica rubber composites. Macromolecules 2011, 44, 4366-4381. [CrossRef]

7. Song, Y.; Yu, J.; Dai, D.; Song, L.; Jiang, N. Effect of silica particles modified by in-situ and ex-situ methods on the reinforcement of silicone rubber. Mater. Des. 2014, 64, 687-693. [CrossRef]

8. Kaewsakul, W.; Sahakaro, K.; Dierkes, W.K.; Noordermeer, J.W. Mechanistic aspects of silane coupling agents with different functionalities on reinforcement of silica-filled natural rubber compounds. Polym. Eng. Sci. 2015, 55, 836-842. [CrossRef]

9. Wu, F.; Zhang, S.; Chen, Z.; Zhang, B.; Yang, W.; Liu, Z.; Yang, M. Interfacial relaxation mechanisms in polymer nanocomposites through the rheological study on polymer/grafted nanoparticles. Polymer 2016, 90, 264-275. [CrossRef]

10. Chen, Z.; Li, L.; Xiong, Z. Investigation on the interfacial behaviour between the rubber-cement matrix of the rubberized concrete. J. Clean. Prod. 2019, 209, 1354-1364. [CrossRef]

11. Galindo-Rosales, F.J.; Moldenaers, P.; Vermant, J. Assessment of the dispersion quality in polymer nanocomposites by rheological methods. Macromol. Mater. Eng. 2011, 296, 331-340. [CrossRef]

12. Hobbie, E.K. Shear rheology of carbon nanotube suspensions. Rheol. Acta 2010, 49, 323-334. [CrossRef]

13. Harwood, J.; Payne, A.; Whittaker, R. Stress-softening and reinforcement of rubber. J. Macromol. Sci. Part B Phys. 1971, 5, 473-486. [CrossRef]

14. Harwood, J.; Mullins, L.; Payne, A.R. Stress softening in natural rubber vulcanizates. Part II. Stress softening effects in pure gum and filler loaded rubbers. J. Appl. Polym. Sci. 1965, 9, 3011-3021. [CrossRef]

15. Medalia, A.I. Electrical conduction in carbon black composites. Rubber Chem. Technol. 1986, 59, $432-454$. [CrossRef]

16. Merabia, S.; Sotta, P.; Long, D.R.J.M. A microscopic model for the reinforcement and the nonlinear behavior of filled elastomers and thermoplastic elastomers (Payne and Mullins effects). Macromolecules 2008, 41, 8252-8266. [CrossRef]

17. Araujo-Morera, J.; Hernández Santana, M.; Verdejo, R.; López-Manchado, M.A. Giving a Second opportunity to tire waste: An alternative path for the development of sustainable self-healing styrene-butadiene rubber compounds overcoming the magic triangle of tires. Polymers 2019, 11, 2122. [CrossRef]

18. Capezza, A.; Andersson, R.L.; Ström, V.; Wu, Q.; Sacchi, B.; Farris, S.; Hedenqvist, M.S.; Olsson, R.T. Preparation and comparison of reduced graphene oxide and carbon nanotubes as fillers in conductive natural rubber for flexible electronics. ACS Omega 2019, 4, 3458-3468. [CrossRef]

19. Zhang, C.; Tang, Z.; Guo, B.; Zhang, L. Significantly improved rubber-silica interface via subtly controlling surface chemistry of silica. Compos. Sci. Technol. 2018, 156, 70-77. [CrossRef] 
20. Mohammed, B.S.; Awang, A.B.; San Wong, S.; Nhavene, C.P. Properties of nano silica modified rubbercrete. J. Clean. Prod. 2016, 119, 66-75. [CrossRef]

21. Tang, Z.; Huang, J.; Wu, X.; Guo, B.; Zhang, L.; Liu, F. Interface engineering toward promoting silanization by ionic liquid for high-performance rubber/silica composites. Ind. Eng. Chem. Res. 2015, 54, 10747-10756. [CrossRef]

22. Kumar, S.; Singh, G.; Thareja, P. Surface chemistry driven dynamic rheology, microstructure of fumed and colloidal silica particles in nematic liquid crystals. J. Mol. Liq. 2020, 314, 113623. [CrossRef]

23. Shanmugharaj, A.; Bhowmick, A.K. Dynamic mechanical properties of styrene-butadiene rubber vulcanizate filled with electron beam modified surface-treated dual-phase filler. J. Appl. Polym. Sci. 2003, 88, 2992-3004. [CrossRef]

24. Nah, C.; Huh, M.Y.; Rhee, J.M.; Yoon, T.H. Plasma surface modification of silica and its effect on properties of styrene-butadiene rubber compound. Polym. Int. 2002, 51, 510-518. [CrossRef]

25. Jiang, J.; Wang, W.; Shen, H.; Wang, J.; Cao, J. Characterization of silica particles modified with $\gamma$-methacryloxypropyltrimethoxysilane. Appl. Surf. Sci. 2017, 397, 104-111. [CrossRef]

26. Kim, Y.-J.; Ha, S.-W.; Jeon, S.-M.; Yoo, D.W.; Chun, S.-H.; Sohn, B.-H.; Lee, J.-K. Fabrication of triacetylcellulose $-\mathrm{SiO}_{2}$ nanocomposites by surface modification of silica nanoparticles. Langmuir 2010, 26, 7555-7560. [CrossRef]

27. Chen, L.; Jia, Z.; Tang, Y.; Wu, L.; Luo, Y.; Jia, D. Novel functional silica nanoparticles for rubber vulcanization and reinforcement. Compos. Sci. Technol. 2017, 144, 11-17. [CrossRef]

28. Dohi, H.; Horiuchi, S. Locating a silane coupling agent in silica-filled rubber composites by EFTEM. Langmuir 2007, 23, 12344-12349. [CrossRef]

29. Tan, J.; Cheng, H.; Wei, L.; Wei, C.; Xing, Y.; Gui, X. Using low-rank coal slime as an eco-friendly replacement for carbon black filler in styrene butadiene rubber. J. Clean. Prod. 2019, 234, 949-960. [CrossRef]

30. Lung, C.Y.K.; Matinlinna, J.P. Aspects of silane coupling agents and surface conditioning in dentistry: An overview. Dent. Mater. 2012, 28,467-477. [CrossRef]

31. Hallett, J.P.; Welton, T. Room-temperature ionic liquids: Solvents for synthesis and catalysis. 2. Chem. Rev. 2011, 111, 3508-3576. [CrossRef]

32. Singh, S.K.; Savoy, A.W.J.J.o.M.L. Ionic liquids synthesis and applications: An overview. J. Mol. Liq. 2020, 297, 112038. [CrossRef]

33. Shakeel, A.; Mahmood, H.; Farooq, U.; Ullah, Z.; Yasin, S.; Iqbal, T.; Chassagne, C.; Moniruzzaman, M. Rheology of pure ionic liquids and their complex fluids: A review. ACS Sustain. Chem. Eng. 2019, 7, 13586-13626. [CrossRef]

34. Lei, J.; Gao, Y.; Zhao, X.; Zhu, Y.; Zhang, C.; Ma, Y.; Zhao, K.; Du, F. The dilational rheology and splashing behavior of ionic liquid-type imidazolium Gemini surfactant solutions: Impact of alkyl chain length. J. Mol. Liq. 2019, 283, 725-735. [CrossRef]

35. Green, M.D.; Long, T.E. Designing imidazole-based ionic liquids and ionic liquid monomers for emerging technologies. Polym. Rev. 2009, 49, 291-314. [CrossRef]

36. Ghandi, K. A review of ionic liquids, their limits and applications. Green Sustain. Chem. 2014, 4, 44-53. [CrossRef]

37. Ye, Y.; Wang, H.; Bi, S.; Xue, Y.; Xue, Z.; Liao, Y.; Zhou, X.; Xie, X.; Mai, Y. Enhanced ion transport in polymer-ionic liquid electrolytes containing ionic liquid-functionalized nanostructured carbon materials. Carbon 2015, 86, 86-97. [CrossRef]

38. Maciejewska, M.; Zaborski, M. Ionic liquids as coagents for sulfur vulcanization of butadiene-styrene elastomer filled with carbon black. Polym. Bull. 2018, 75, 4499-4514. [CrossRef]

39. Kreyenschulte, H.; Richter, S.; Götze, T.; Fischer, D.; Steinhauser, D.; Klüppel, M.; Heinrich, G. Interaction of 1-allyl-3-methyl-imidazolium chloride and carbon black and its influence on carbon black filled rubbers. Carbon 2012, 50, 3649-3658. [CrossRef]

40. Laskowska, A.; Marzec, A.; Boiteux, G.; Zaborski, M.; Gain, O.; Serghei, A. Effect of imidazolium ionic liquid type on the properties of nitrile rubber composites. Polym. Int. 2013, 62, 1575-1582. [CrossRef]

41. Xu, H.; Tong, F.; Yu, J.; Wen, L.; Zhang, J.; He, J. A one-pot method to prepare transparent poly (methyl methacrylate)/montmorillonite nanocomposites using imidazolium-based ionic liquids. Polym. Int. 2012, 61, 1382-1388. [CrossRef] 
42. Zhao, L.; Li, Y.; Cao, X.; You, J.; Dong, W. Multifunctional role of an ionic liquid in melt-blended poly (methyl methacrylate)/multi-walled carbon nanotube nanocomposites. Nanotechnology 2012, 23, 255702. [CrossRef] [PubMed]

43. Hussain, M.; Yasin, S.; Adnan Akram, M.; Xu, H.; Song, Y.; Zheng, Q. Influence of ionic liquids on structure and rheological behaviors of silica-filled butadiene rubber. Ind. Eng. Chem. Res. 2019, 58, 18205-18212. [CrossRef]

44. Flory, P.J.; Rehner Jr, J. Statistical mechanics of cross-linked polymer networks I. Rubberlike elasticity. J. Chem. Phys. 1943, 11, 512-520. [CrossRef]

45. Marzocca, A.; Garraza, A.R.; Mansilla, M. Evaluation of the polymer-solvent interaction parameter $\chi$ for the system cured polybutadiene rubber and toluene. Polym. Test. 2010, 29, 119-126. [CrossRef]

46. Zhang, X.; Xue, X.; Jia, H.; Wang, J.; Ji, Q.; Xu, Z. Influence of ionic liquid on the polymer-filler coupling and mechanical properties of nano-silica filled elastomer. J. Appl. Polym. Sci. 2017, 134, 44478. [CrossRef]

47. Song, Y.; Zeng, L.; Zheng, Q. Reconsideration of the rheology of silica filled natural rubber compounds. J. Phys. Chem. B 2017, 121, 5867-5875. [CrossRef]

48. Zhong, B.; Jia, Z.; Hu, D.; Luo, Y.; Guo, B.; Jia, D. Surface modification of halloysite nanotubes by vulcanization accelerator and properties of styrene-butadiene rubber nanocomposites with modified halloysite nanotubes. Appl. Surf. Sci. 2016, 366, 193-201. [CrossRef]

49. Lungwitz, R.; Linder, T.; Sundermeyer, J.; Tkatchenko, I.; Spange, S. Synthesis of chemisorbed imidazolium and phosphonium cations by reaction of ionic liquid precursors with silica. Chem. Commun. 2010, 46, 5903-5905. [CrossRef]

50. Marwanta, E.; Mizumo, T.; Nakamura, N.; Ohno, H. Improved ionic conductivity of nitrile rubber/ionic liquid composites. Polymer 2005, 46, 3795-3800. [CrossRef]

51. Zhang, C.; Mi, X.; Tian, J.; Zhang, J.; Xu, T. Supported ionic liquid silica as curing agent for epoxy composites with improved mechanical and thermal properties. Polymers 2017, 9, 478. [CrossRef] [PubMed]

52. Fu, S.-Y.; Feng, X.-Q.; Lauke, B.; Mai, Y.-W. Effects of particle size, particle/matrix interface adhesion and particle loading on mechanical properties of particulate-polymer composites. Compos. Part B Eng. 2008, 39, 933-961. [CrossRef]

53. Szadkowski, B.; Marzec, A.; Zaborski, M. Effect of in situ silanization of multiwalled carbon nanotubes on the properties of NBR/MWCNT-OH composites. Polym. Plast. Technol. Mater. 2019, 58, 1327-1341. [CrossRef]

54. Weng, P.; Tang, Z.; Guo, B. Effects of Alkalinity of Ionic Liquid on Catalyzed Silanization in Rubber/Silica Composites. Ind. Eng. Chem. Res. 2019, 58, 18654-18662. [CrossRef]

55. Liu, J.; Gao, Y.; Cao, D.; Zhang, L.; Guo, Z. Nanoparticle dispersion and aggregation in polymer nanocomposites: Insights from molecular dynamics simulation. Langmuir 2011, 27, 7926-7933. [CrossRef]

56. Blume, A.; Thibault-Starzyk, F. Deciphering the silica/silane reaction mechanism for the development of a new generation of low rolling resistance tires: Part 1-Characterization by in situ IR spectroscopy. Rubber Fibres Plast. Int. 2017, 12, 152-157.

57. Xu, Y.; Xu, H.; Zheng, Q.; Song, Y. Influence of ionic liquid on glass transition, dynamic rheology, and thermal stability of poly (methyl methacrylate)/silica nanocomposites. J. Appl. Polym. Sci. 2019, 136, 48007. [CrossRef]

58. Huang, M.; Tunnicliffe, L.B.; Thomas, A.G.; Busfield, J.J. The glass transition, segmental relaxations and viscoelastic behaviour of particulate-reinforced natural rubber. Eur. Polym. J. 2015, 67, 232-241. [CrossRef]

59. Xu, H.; Xia, X.; Hussain, M.; Song, Y.; Zheng, Q. Linear and nonlinear rheological behaviors of silica filled nitrile butadiene rubber. Polymer 2018, 156, 222-227. [CrossRef]

60. Taguet, A.; Cassagnau, P.; Lopez-Cuesta, J.-M. Structuration, selective dispersion and compatibilizing effect of (nano) fillers in polymer blends. Prog. Polym. Sci. 2014, 39, 1526-1563. [CrossRef]

61. Ou, Y.C.; Yu, Z.Z.; Vidal, A.; Donnet, J. Effects of alkylation of silicas on interfacial interaction and molecular motions between silicas and rubbers. J. Appl. Polym. Sci. 1996, 59, 1321-1328. [CrossRef]

62. Saha, T.; Bhowmick, A.K. Influence of nanofiller on thermal degradation resistance of hydrogenated nitrile butadiene rubber. Rubber Chem. Technol. 2019, 92, 263-285. [CrossRef]

63. Gao, W.; Lu, J.; Song, W.; Hu, J.; Han, B. Solution mechanochemical approach for preparing high-dispersion $\mathrm{SiO}_{2}-g$-SSBR and the performance of modified silica/SSBR composites. Ind. Eng. Chem. Res. 2019, 58, 7146-7155. [CrossRef]

64. Maciejewska, M.; Walkiewicz, F.; Zaborski, M. Novel ionic liquids as accelerators for the sulfur vulcanization of butadiene-styrene elastomer composites. Ind. Eng. Chem. Res. 2013, 52, 8410-8415. [CrossRef] 
65. Xia, X.; Wu, Z.; Wang, W.; Shangguan, Y.; Zheng, Q. A facile and environmentally friendly approach to fabricate hybrid crosslinked nitrile butadiene rubber with comprehensively improved mechanical performances by incorporating sacrificial ionic bonds. Polymer 2019, 161, 55-63. [CrossRef]

66. Xu, H.; Fan, X.; Song, Y.; Zheng, Q. Reinforcement and Payne effect of hydrophobic silica filled natural rubber nanocomposites. Compos. Sci. Technol. 2020, 187, 107943. [CrossRef]

67. Marzec, A.; Laskowska, A.; Boiteux, G.; Zaborski, M.; Gain, O.; Serghei, A. The impact of imidazolium ionic liquids on the properties of nitrile rubber composites. Eur. Polym. J. 2014, 53, 139-146. [CrossRef]

68. Yang, S.; Tian, J.; Bian, X.; Wu, Y. High performance NBR/fly ash composites prepared by an environment-friendly method. Compos. Sci. Technol. 2020, 186, 107909. [CrossRef]

69. Xu, Y.; Xu, H.; Zheng, Q.; Song, Y. Influence of ionic liquids on rheological behaviors of polyisoprene rubber/silica compounds. Polymer 2019, 183, 121898. [CrossRef]

70. Fan, X.; Xu, H.; Zhang, Q.; Song, Y.; Zheng, Q. Insight into the weak strain overshoot of carbon black filled natural rubber. Polymer 2019, 167, 109-117. [CrossRef]

71. Song, Y.; Zeng, L.; Zheng, Q. Understanding the reinforcement and dissipation of natural rubber compounds filled with hybrid filler composed of carbon black and silica. Chin. J. Polym. Sci. 2017, 35, 1436-1446. [CrossRef]

72. Van de Walle, A.; Tricot, C.; Gerspacher, M. Modeling carbon black reinforcement in rubber compounds. Kautsch. Gummi Kunstst. 1996, 49, 172-179.

73. Divoux, T.; Barentin, C.; Manneville, S. Stress overshoot in a simple yield stress fluid: An extensive study combining rheology and velocimetry. Soft Matter 2011, 7, 9335-9349. [CrossRef]

Publisher's Note: MDPI stays neutral with regard to jurisdictional claims in published maps and institutional affiliations. 